Article

\title{
A Hybrid MCDM Model to Select Optimal Hosts of Variety Shows in the Social Media Era
}

\author{
Lee-Chun $\mathrm{Wu}^{1}$, Kuei-Lun Chang ${ }^{2, *}$ and Sen-Kuei Liao ${ }^{3}$ \\ 1 School of Economics and Management, Sanming University, Sanming 365004, China; \\ wu0933155@yahoo.com.tw \\ 2 Department of New Media and Communication Administration, Ming Chuan University, \\ Taipei 11103, Taiwan \\ 3 Department of Business Management, National Taipei University of Technology, Taipei 10608, Taiwan; \\ skliao@ntut.edu.tw \\ * Correspondence: cs821@yahoo.com.tw
}

Received: 28 November 2019; Accepted: 2 January 2020; Published: 8 January 2020

check for Abstract: The selection of the optimal variety show hosts is a key to television stations. However,
no study has a deal with this issue. In this paper, a hybrid multiple criteria decision-making
(MCDM) model based on the fuzzy Delphi method, decision-making trial and evaluation laboratory
(DEMATEL), analytic network process (ANP), and technique for order preference by similarity to
ideal solution (TOPSIS) to choose optimal hosts of variety shows for television stations in the social
media era was developed. The fuzzy Delphi method was taken as a screening tool for the selection
criteria of variety show hosts. Then, DEMATEL was applied to verify the interdependencies between
the perspectives. According to the interdependencies, ANP was employed to obtain weights. Finally,
TOPSIS ranked the alternatives. The selection criteria were gathered from previous researches and
discussions with senior executives of television stations. By the fuzzy Delphi method, 12 criteria were
identified. Based on the past study and consultations with four senior executives, we classified 12
essential criteria into four perspectives to develop the hierarchy for the variety show host selection.
Under the hierarchy base on four perspectives and 12 criteria, managers of television stations could
select the optimal variety show hosts more effectively. The usability and efficiency of the proposed
model were also considered by a case study. We offered a distinct contribution to the prior studies by
providing a model in the variety show host selection field. In the context of social media competition,
this study also added the selection criteria from Internet celebrities.

Keywords: variety show host; social media; the fuzzy Delphi method; DEMATEL; ANP; TOPSIS

\section{Introduction}

The media landscape is crowded, with numerous shows on television as well as on other platforms. A host that can bring a big personality and can stimulate and drive interesting or humorous banter with guests is essential. In practice, a host's style must closely align with the content of the show; this can drive ratings. Moreover, the host must captivate the audience to draw viewers and ensure the success of the show. Jia [1] pointed out that hosts are an image and a representative for television stations. Therefore, hosts are undoubtedly an effective role in increasing the influential coverage of television programs and achieving the optimum spreading efficiency. Aznárez-Mauleón [2] declared that hosts in television talk shows are the vital participants who are in charge of the show flowing, topics, and keeping away from silent gaps. Wang [3] showed that hosts are dominant roles in the character-type talk shows, and their language skills determine the content and quality of talk shows.

Variety shows are a staple of prime-time television programming that generate considerable revenue. As the number of broadcast hours devoted to variety shows has continually increased over 
the years, audience interest has also increased. A host greatly influences the variety show's quality. In the highly competitive television industry, a host with a compelling image and performance style is critical to building a successful brand.

Social media continues to attract a large number of consumers [4]. Additionally, social media plays numerous vital roles in a community. It offers a space in which community members can perform and be known [5]. The emergence of social media has made Internet celebrities appear in various fields and platforms. Moreover, the popularity of social media has also given rise to Internet celebrities. Now, they represent a new form of celebrity with considerable influence. Hwang and Zhang [6] compared such a role with traditional celebrities, and they found that Internet celebrities became famous through social network sites (SNS) and marketers have recognized their advertising power.

Television hosts should actively interact with audiences through social media. However, studies have not investigated the necessary conditions and abilities of a host in the social media era when discussing the selection of variety show hosts. Therefore, this study examined the selection of variety show hosts in the context of social media competition. We added the criteria of the success of an Internet celebrity, such as the number of Facebook posts shared, the number of YouTube channel subscriptions, and page views.

In the fickle business environment, enterprises are increasingly treating their human resources as a potential root of sustainable competitive advantage [7]. Personnel selection is a complicated multiple criteria decision-making (MCDM) problem. Selecting the most suitable personnel impacts an enterprise's competitiveness [8]. Complicated decision problems force decision-makers to find out new approaches for supporting decision making [9]. In this study, we developed a hybrid MCDM model based on the fuzzy Delphi method, decision-making trial and evaluation laboratory (DEMATEL), analytic network process (ANP), and technique for order preference by similarity to ideal solution (TOPSIS) to select the optimal hosts of variety shows for television stations. The Delphi method is quite useful to identify the selection criteria for variety show hosts. However, the Delphi method has been commented on regarding its low convergence to conclusions, the lengthy procedure of interrogation, and the loss of important data from respondents $[10,11]$. Hence, we firstly served the fuzzy Delphi method as a screening tool for the selection criteria of variety show hosts. More unbiased selection criteria can be identified via the fuzzy Delphi method. Second, DEMATEL was applied to verify interdependencies between the perspectives. DEMATEL can present cause-effect relations among factors by a structurally intelligible and quantifiable model. It has been successfully utilized in many fields [12]. Awang et al. [13] also pointed out that DEMATEL is the best way to clarify the interrelationships of criteria. Third, ANP does not own strict hierarchical relationships. Relationships between the levels or the same level are closer to reality [14]. According to interdependencies, ANP was employed to acquire respective weights. TOPSIS, one of the most useful MCDM methods, is very easy to understand and utilize [15]. To overcome ANP's drawback, more pairwise comparisons are needed that also take more time; thus, the ranking of alternatives was determined by TOPSIS.

The other parts of this study are arranged as below. Then, the literature on personnel selection is briefly reviewed. Next, the methodology is mentioned. Section 4 presents the integrated selection model for the optimal hosts of variety shows. Section 5 is the conclusion.

\section{Literature Review}

This part presents a summary of the prior studies on MCDM methods in personnel selection applications, as shown in Table 1. It should be stated that no research has dealt with the selection issue of variety show hosts. However, this study fills the gap by applying a hybrid MCDM model in this specific application area. Previous studies suffer from some weaknesses about the methodologies, including not pointing out how to identify the selection criteria, not giving consideration to the interdependencies among the factors in the hierarchy, and not figuring out the interdependent relations between factors through any quantitative approaches. 
Table 1. The literature on MCDM methods for personnel selection.

\begin{tabular}{|c|c|c|c|}
\hline Year & Contributor(s) & Topic & Applied Method(s) \\
\hline 2014 & $\begin{array}{c}\text { Ballı and } \\
\text { Korukoğlu [15] }\end{array}$ & Basketball player & $\begin{array}{l}\text { Fuzzy analytic hierarchy process } \\
\text { (FAHP) and TOPSIS }\end{array}$ \\
\hline 2014 & Dadelo et al. [16] & $\begin{array}{l}\text { Professional basketball } \\
\text { player }\end{array}$ & $\begin{array}{l}\text { Wisdom-of-crowds principles } \\
\text { and TOPSIS }\end{array}$ \\
\hline 2014 & $\begin{array}{l}\text { Keršulienè and } \\
\text { Turskis [17] }\end{array}$ & Chief accounting officer & $\begin{array}{l}\text { Principles of fusion of fuzzy } \\
\text { information, additive ratio assessment } \\
\text { with fuzzy numbers (ARAS-F), fuzzy } \\
\text { weighted-product model, and analytic } \\
\text { hierarchy process (AHP) }\end{array}$ \\
\hline 2015 & Chang [18] & $\begin{array}{l}\text { Public relations } \\
\text { personnel }\end{array}$ & $\begin{array}{l}\text { The fuzzy Delphi method, ANP, } \\
\text { and TOPSIS }\end{array}$ \\
\hline 2015 & Chang et al. [19] & Tour guide & $\begin{array}{l}\text { The fuzzy Delphi method, ANP, } \\
\text { and TOPSIS }\end{array}$ \\
\hline 2015 & Karabasevic et al. [20] & Mining engineer & $\begin{array}{l}\text { Step-wise weight assessment ratio } \\
\text { analysis (SWARA) and multi-objective } \\
\text { optimization by ratio analysis plus the } \\
\text { full multiplicative form } \\
\text { (MULTIMOORA) }\end{array}$ \\
\hline 2015 & Sang et al. [21] & System analyst engineer & $\begin{array}{l}\text { Fuzzy TOPSIS (FTOPSIS) based on the } \\
\text { Karnik-Mendel (KM) algorithm }\end{array}$ \\
\hline 2016 & $\begin{array}{l}\text { Asuquo and } \\
\text { Onuodu [22] }\end{array}$ & Academic staff & FAHP \\
\hline 2016 & Erdem [23] & $\begin{array}{l}\text { Information technology } \\
\text { personnel (Junior } \\
\text { developer) }\end{array}$ & FAHP \\
\hline 2016 & Karabasevic et al. [24] & Sales manager & $\begin{array}{l}\text { SWARA and additive ratio } \\
\text { assessment (ARAS) }\end{array}$ \\
\hline 2016 & Kosareva et al. [25] & Security guard & $\begin{array}{l}\text { KEmeny Median Indicator Rank } \\
\text { Accordance (KEMIRA) }\end{array}$ \\
\hline 2017 & Stanujkic et al. [26] & Promoter & $\begin{array}{l}\text { New approach based on adapted } \\
\text { weighted sum and SWARA }\end{array}$ \\
\hline 2017 & Urosevic et al. [27] & Sales manager & $\begin{array}{l}\text { SWARA and weighted aggregates sum } \\
\text { product assessment (WASPAS) }\end{array}$ \\
\hline 2018 & $\begin{array}{l}\text { Deliktas and } \\
\text { Üstun [28] }\end{array}$ & Industrial engineers & FAHP and FTOPSIS \\
\hline 2018 & Ji et al. [29] & Sales supervisor & $\begin{array}{l}\text { Projection-based an acronym in } \\
\text { Portuguese of interactive and } \\
\text { multi-criteria decision-making (TODIM) }\end{array}$ \\
\hline 2019 & Ding et al. [30] & Middle manager & Fuzzy MCDM \\
\hline 2019 & Liao et al. [31] & Celebrity endorser & $\begin{array}{l}\text { The fuzzy Delphi method, DEMATEL, } \\
\text { ANP, and TOPSIS }\end{array}$ \\
\hline 2019 & Nabeeh et al. [32] & Manager & Neutrosophic AHP and TOPSIS \\
\hline 2019 & Pehlivan et al. [33] & $\begin{array}{l}\text { National football team } \\
\text { player }\end{array}$ & $\begin{array}{l}\text { FAHP, FTOPSIS, and integrated these } \\
\text { two methods }\end{array}$ \\
\hline 2019 & $\begin{array}{l}\text { Yalçın and } \\
\text { Pehlivan [34] }\end{array}$ & Blue-collar personnel & $\begin{array}{l}\text { Fuzzy COmbinative Distance-based } \\
\text { Assessment (CODAS) method using the } \\
\text { fuzzy envelopes of the hesitant fuzzy } \\
\text { linguistic term sets (HFLTSs) based on } \\
\text { comparative linguistic } \\
\text { expressions (CLEs) }\end{array}$ \\
\hline
\end{tabular}




\section{Methodology}

Multiple criteria decision analysis (MCDA) approaches are via expert insights to create frameworks for better decision making [35]. In this section, the fuzzy Delphi method, DEMATEL, ANP, and TOPSIS are explained for determining the optimal variety show hosts for television stations in the social media era.

\subsection{Conceptual Framework}

This study can assist television stations managers in selecting the optimal variety show hosts in the social media era, and the conceptual framework of this research is as follows:

(1) First level: Objective

Select the optimal variety show hosts for television stations in the era of social media.

(2) Second level: Perspectives

Crucial criteria are classified into several perspectives according to the relevant literature and interviews with the program department supervisors of television stations.

(3) Third level: Criteria

Review relevant studies of television hosts. Additionally, investigate relevant conditions and abilities of hosts in the social media era as well as the criteria that create an Internet celebrity. Subsequently, the selection criteria for hosts of television variety shows are compiled, and a 9-item questionnaire is designed according to the fuzzy Delphi method, which is then distributed to program department supervisors and senior producers of television stations. Respondents rate the importance of criteria with a score of 1 to 9 according to their personal, professional, and practical work experiences. Crucial criteria are retained according to their geometric mean from experts.

(4) Fourth level: Alternatives

Alternatives are the variety show hosts of the case company.

\subsection{Representation of the Selection Model}

The proposed model is on the basis of the fuzzy Delphi method, DEMATEL, ANP, and TOPSIS for determining the optimal variety show hosts for television stations in the social media era. We first gathered the selection criteria for variety show hosts by literature review and experts' interviews. The fuzzy Delphi method was utilized for screening the selection criteria. On the basis of past studies and executives' opinions, the hierarchy was developed. Then, DEMATEL was applied to verify interdependencies between the perspectives. According to interdependencies, ANP was employed to acquire respective weights. At last, TOPSIS was used for the ranking of alternatives. The selection procedure is shown in Figure 1. 


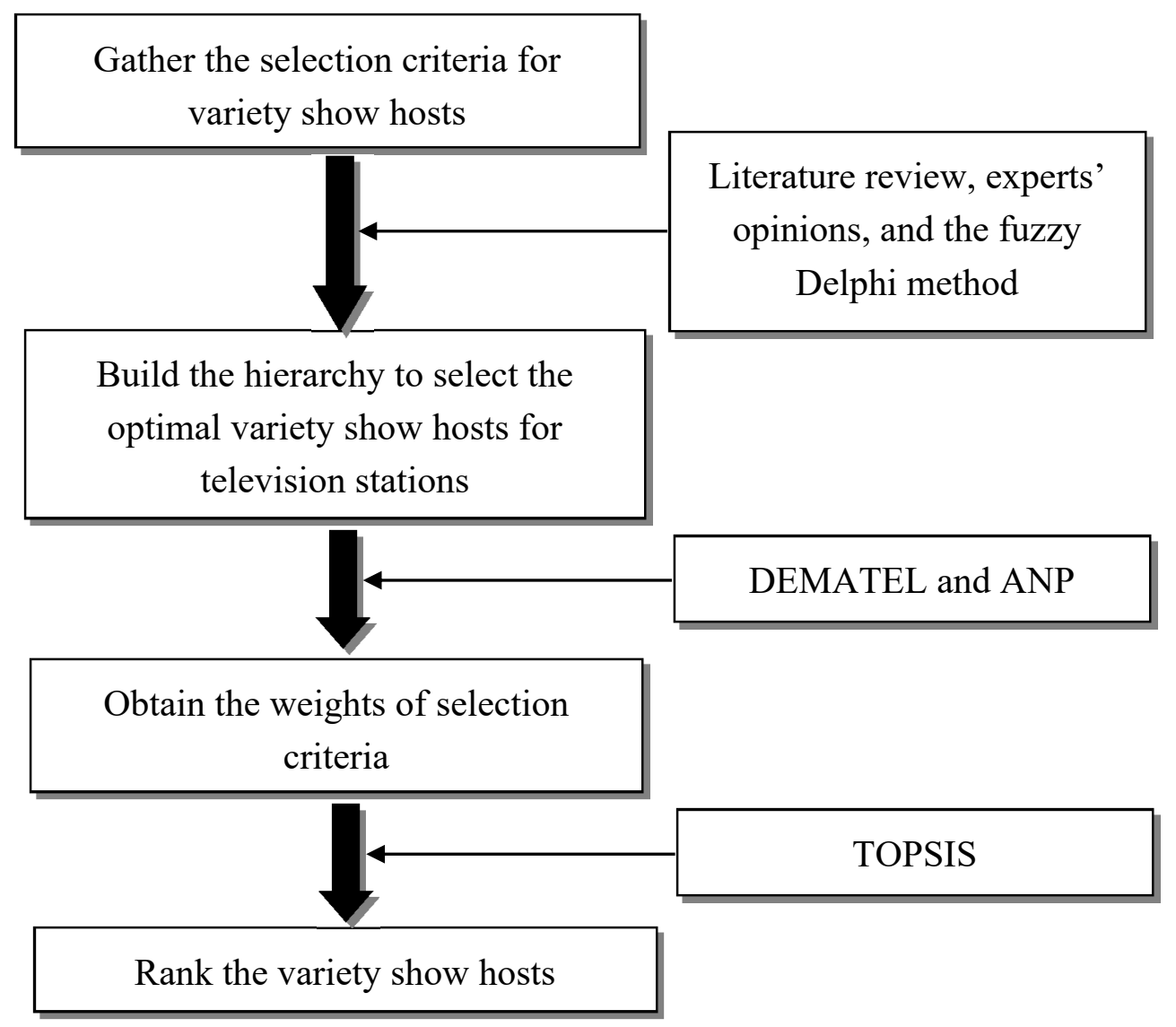

Figure 1. Steps of the selection model for variety show hosts.

\subsection{Fuzzy Delphi Method}

The Delphi method has proven to be effective in forecasting technological trends [36]. It attempts to reach expert consensus via behavioral feedback in brainstorming. Through results from sequential rounds of survey administration, the group members begin to understand other experts' perspectives, adjusting their knowledge, and developing a full understanding of the topic. The success of the Delphi method relies on whether the experts are fully committed. To ensure a smooth implementation of the Delphi method, it is necessary to establish a list of experts, discuss the research issues with the invited experts, and obtain a commitment from the potential group members. The expert members of a Delphi method do not change across questionnaire administration. Members cannot suddenly withdraw and cannot have direct face-to-face discussions. By repeatedly eliciting opinions and encouraging opinion modification, the decision-making group reaches a consensus [37,38].

However, studies [10,11,36,39-41] have the declared the disadvantages of the Delphi method. For example, the research time can be quite long, especially as the number of iterations increases. Respondents may drop out of the process. Even when the narrative text of the questionnaire is clear, it is difficult to avoid ambiguity. Besides, it is easy for the participants to misunderstand unclear instructions from the questionnaire.

To overcome such disadvantages, researchers [42-44] have improved it by the fuzzy concept. Chang et al. [45] presented that the Delphi method fails to deal with the fuzziness in respondents' opinions. The fuzzy Delphi method can identify the criteria for resolving many uncertain problems. Zhang [14] also expressed that the conclusions acquired by the fuzzy Delphi method are objective and reasonable. Moreover, the investigation time and costs are reduced. This study used the fuzzy Delphi method to obtain the selection criteria. The geometric mean can better represent the majority of the decision-makers and can better represent more objective and fair criteria. The criterion is considered 
significant when its importance is over $80 \%$ [46]. In other words, if a 9-point Likert scale questionnaire is used, a geometric mean that is greater than 7.2 is classified as an important criterion.

$$
L_{G}=\left(L_{1} \times L_{2} \times \cdots \times L_{n}\right)^{1 / n}
$$

where $L_{i}$ denotes the importance rating of the criteria by the $i$-th expert $(i=1,2, \ldots, n) . L_{G}=$ geometric mean value.

\subsection{DEMATEL}

DEMATEL uses complex systems by directly comparing the relationship between factors to utilize matrices to calculate the causal relationships between them. Based on professional knowledge, the decision-makers give scores of "no influence", "low influence", "medium influence", "high influence", and "very high influence" to the relationship between factors. DEMATEL assists in decision making by expressing the causal relationship between factors in complicated systems and the intensity of their effects. In other words, this method transforms complicated systems into well-defined causal relationships. The following is the procedure for operating DEMATEL [12,31,47-50].

(1) Build the initial direct-relation matrix

The decision-makers determine the extent of influence of the two factors and fill in the corresponding position, which generates a direct-relation table and integrates the decision-makers' results to produce an initial direct-relation matrix. The average matrix is constructed $A=\left[a_{i j}\right]$ :

$$
a_{i j}=\frac{1}{H} \sum_{k=1}^{H} x_{i j}^{k} .
$$

$x_{i j}$ is the degree to which the decision-maker evaluation factor $i$ influences factor $j$. For $i=$ $j$, all the diagonal elements values are 0 . For each decision-maker, a $n \times n$ positive matrix can be developed as $X^{k}=\left[X_{i j}^{k}\right]$, where $k$ is the number of decision-makers with $1 \leq k \leq H$, and $n$ is the number of perspectives.

(2) Establish the normalized initial direct-relation matrix

Normalize the initial direct-relation matrix obtained by the previous step to obtain the matrix $X$. $X$ is generated from $A . X=A \times S$ where $S=\frac{1}{\max _{1 \leq i \leq n} \sum_{j=1}^{n} a_{i j}}$. Each element in $X$ falls between 0 and 1 .

(3) Establish the total-influence relation matrix

When matrix $X$ is known, the total-influence relation matrix $T$ can be obtained from the formula $\left(T=X(I-X)^{-1}\right)$, where $I$ is an identity matrix with a diagonal value of 1 .

(4) Establish the threshold value

Establish the threshold value according to the total-influence relation matrix. By doing so, the influence that is too small in the matrix can be eliminated, and a more concise causal relationship between factors can be obtained.

Recently, practitioners and researchers are interested in DEMATEL and it is applied it widely due to its ability to handle complicated relationships [51]. In this paper, DEMATEL was utilized to verify interdependencies between the perspectives.

\subsection{ANP}

ANP, an extension of AHP, is a comprehensive approach that can capture the outcome of dependencies between elements [52]. Comparing to AHP, ANP ponders interdependence and thus is superior for solving real-world situations [53]. There are four major steps of ANP: 


\section{(1) Construct the hierarchy}

The problem is structured in a hierarchy including a goal, perspectives, criteria, and alternatives. The contents of the hierarchy can be determined by appropriate methods, such as eliciting brainstormed opinions from decision-makers, or by a literature survey.

(2) Complete pairwise comparison

Decision-makers make a series of pairwise comparisons to obtain the relative importance of factors. A 9-point scale is applied to compare two factors according to their interdependency. All decision-makers' preferences should be inputs to a geometric mean calculation to establish each pairwise comparison. We compare a set of $n$ factors pairwise based on their relative importance weights, where the factors are presented by $a_{1}, a_{2}, \ldots, a_{n}$ and the weights are indicated by $w_{1}, w_{2}, \ldots$, $w_{n}$. The pairwise comparisons can be shown by questionnaires with subjective perception as:

$$
A=\left[\begin{array}{cccc}
a_{11} & a_{1 j} & \ldots & a_{1 n} \\
a_{i 1} & a_{i j} & \ldots & a_{i n} \\
\vdots & \vdots & \vdots & \vdots \\
a_{n 1} & a_{n j} & \ldots & a_{n n}
\end{array}\right]
$$

where $a_{i j}$ is $1 / a_{j i}$ and $a_{i j}=a_{i k} / a_{j k}$.

A weight matrix is illustrated as:

$$
W=\begin{array}{cccc}
w_{1} & w_{j} & \ldots & w_{n} \\
w_{1} & w_{i} \\
\vdots \\
w_{n}
\end{array}\left[\begin{array}{cccc}
w_{1} / w_{1} & w_{1} / w_{j} & \ldots & w_{1} / w_{n} \\
w_{i} / w_{1} & w_{i} / w_{j} & \ldots & w_{i} / w_{n} \\
\vdots & \vdots & \vdots & \vdots \\
w_{n} / w_{1} & w_{n} / w_{j} & \ldots & w_{n} / w_{n}
\end{array}\right]
$$

The eigenvector of the observable pairwise comparison matrix provides the weights of the factors at this level, which will be used in the supermatrix.

$$
A w=\lambda_{\max } w
$$

where $A$ is defined as the matrix of pairwise comparison values; $w$ is the priority vector, also called the principal eigenvector, and $\lambda_{\max }$ is the maximum eigenvalue of matrix $A$.

The consistency ratio $(\mathrm{CR})$ is proposed to verify the consistency of the pairwise comparison matrix. If the $C R$ value is less than 0.1 , the pairwise comparison matrix is accepted as consistent.

$$
\mathrm{CR}=\frac{\mathrm{CI}}{\mathrm{RI}} \text { with } \mathrm{CI}=\frac{\lambda_{\max }-n}{n-1}
$$

$\mathrm{CI}$ and RI represent the consistency index and random index, respectively, and $n$ is the number of factors in the matrix.

(3) Solve the supermatrix

ANP utilizes the supermatrix to deal with dependencies among factors. The factors weights are applied to obtain the columns of the supermatrix. A general form of the supermatrix is presented in Figure 2. $C_{m}$ denotes the $m$ th cluster, $e_{m n}$ is the $n$th factor in the $m$ th cluster, and $W_{i j}$ is the principal eigenvector of the influence of the factors compared in the $j$ th cluster to the $i$ th cluster. If the $j$ th cluster has no impact on the $i$ th cluster, then $W_{i j}$ is 0 . The eigenvector obtained in Step 2 is grouped and located in appropriate positions in the supermatrix based on the influences. 


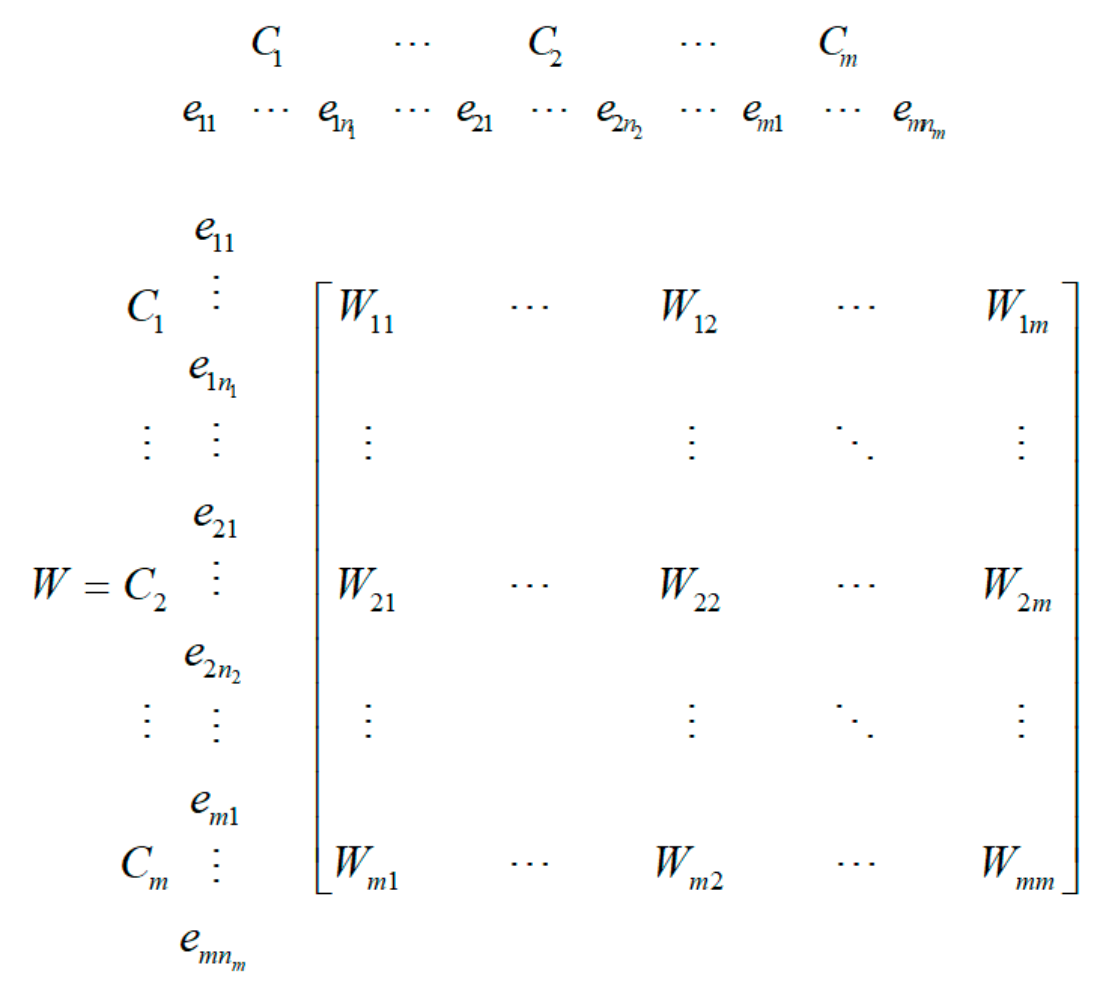

Figure 2. An example of the supermatrix.

The unweighted supermatrix $W$, containing the weights derived from the pairwise comparisons throughout the network, can be also presented as follows:

$$
W=\begin{gathered}
C_{1} \\
C_{2} \\
C_{3}
\end{gathered}\left[\begin{array}{ccc}
C_{1} & C_{2} & C_{3} \\
0 & 0 & W_{13} \\
W_{21} & 0 & 0 \\
0 & W_{32} & W_{33}
\end{array}\right] .
$$

$W_{21}$ is a matrix that illustrates the weights of cluster 2 concerning cluster $1 ; W_{33}$ shows that there is an inner dependence within cluster 3 .

Finally, the weighted supermatrix is stabilized by multiplying the weighted supermatrix by itself until its row values converge to the same value (limiting matrix).

$$
W_{\text {limit }}=\lim _{x \rightarrow \infty}\left(W_{\text {weighted }}\right)^{x} \cong\left(W_{\text {weighted }}\right)^{2 k+1}
$$

Here, $k=$ an arbitrarily large number.

(4) Choose the optimal alternative

Through a synthesis of the limiting matrix and the weights of the alternatives, the global weight of each alternative can be derived. Then, the identified alternatives are ranked per their weights.

We employed ANP here to get weights according to the interdependencies obtained by DEMATEL.

\subsection{TOPSIS}

TOPSIS is an MCDM method developed by Hwang and Yoon in 1981 [54]. The method assumes that all criteria are either monotonically increasing or monotonically decreasing and selects a solution that is closest to the positive ideal solution (PIS) and farthest from the negative ideal solution (NIS) as the ideal solution. Criteria that are benefit criteria exhibit more favorable performance and higher preference values, whereas those that are cost criteria exhibit less favorable performance and lower 
preference values. A PIS is derived by combining the optimal values of all criteria, whereas an NIS is determined by the worst values of all criteria. When determining the alternative to be implemented, Euclidean distance is adopted to get the distance between each alternative and the ideal solution. The TOPSIS procedure is as follows:

(1) Build a normalized evaluation matrix

$$
r_{i j}=\frac{x_{i j}}{\sqrt{\sum_{i=1}^{m} x_{i j}^{2}}}
$$

where $i$ is the alternatives, $j$ is the selection criteria, and $x_{i j}$ is the $i$ alternative under the $j$ criterion to be measured.

(2) Construct a weighted evaluation matrix

Multiply the weight vector by the normalized evaluation matrix to obtain the weighted evaluation matrix. In other words, the weights of selection criteria, $w=\left(w_{1}, w_{2}, \cdots, w_{n}\right)$, multiplied by the normalized evaluation matrix can be expressed as:

$$
v=\left[\begin{array}{cccc}
v_{11} & v_{12} & \ldots & v_{1 n} \\
v_{21} & v_{22} & \ldots & v_{2 n} \\
\vdots & \vdots & \ldots & \vdots \\
v_{m 1} & v_{m 2} & \ldots & v_{m n}
\end{array}\right]=\left[\begin{array}{cccc}
w_{1} r_{11} & w_{2} r_{12} & \ldots & w_{n} r_{1 n} \\
w_{1} r_{21} & w_{2} r_{22} & \ldots & w_{n} r_{2 n} \\
\vdots & \vdots & \ldots & \vdots \\
w_{1} r_{m 1} & w_{2} r_{m 2} & \ldots & w_{n} r_{m n}
\end{array}\right]
$$

(3) Identify PIS $\left(A^{*}\right)$ and NIS $\left(A^{-}\right)$

$$
\begin{aligned}
& A^{*}=\left\{v_{1}^{*}, v_{2}^{*}, \ldots, v_{j}^{*}, \ldots, v_{n}^{*}\right\}=\left\{\left(\max _{i} v_{i j} j \in J\right) i=1, \ldots, m\right\} \\
& A^{-}=\left\{v_{1}^{-}, v_{2}^{-}, \ldots, v_{j}^{-}, \ldots, v_{n}^{-}\right\}=\left\{\left(\min _{i} v_{i j} j \in J\right) i=1, \ldots, m\right\}
\end{aligned}
$$

(4) Compute the Euclidean distance of each alternative from PIS $\left(S_{i}^{*}\right)$ and NIS $\left(S_{i}^{-}\right)$

$$
\begin{aligned}
& S_{i}^{*}=\sqrt{\sum_{j=1}^{n}\left(v_{i j}-v_{i}^{*}\right)^{2}}, i=1, \ldots, m \\
& S_{i}^{-}=\sqrt{\sum_{j=1}^{n}\left(v_{i j}-v_{i}^{-}\right)^{2}}, i=1, \ldots, m
\end{aligned}
$$

(5) Compute the closeness coefficient of each alternative

$$
C_{i}^{*}=\frac{S_{i}^{-}}{S_{i}^{*}+S_{i}^{-}}
$$

We rank the alternatives in descending order of $C_{i}^{*}$.

\section{Empirical Study and Results}

We proposed a hybrid MCDM model containing the fuzzy Delphi method, DEMATEL, ANP, and TOPSIS to select appropriate variety show hosts for television stations in Taiwan. The selecting process is as follows. 


\subsection{Construct the Hierarchy}

The selection criteria for variety show hosts were gathered from previous studies and consultations with senior executives of television stations. Based on a purposive sampling method, two deputy general managers of television stations were contacted and asked to recommend other professionals with plenty of experience in television program production. By the fuzzy Delphi method, a 9-point Likert scale questionnaires were issued. A total of 44 respondents were gathered who on average have more than 10 years of experience in television program production. Respondents are deputy general managers of television stations, deputy general managers of program departments, managers of program departments, directors of program departments, and senior producers of program departments.

The geometric mean of each selection criterion was utilized to denote the consensus of the respondents' evaluation value of the criteria, as shown in Table 2. According to Hwang et al. [46], a geometric mean that is greater than 7.2 is classified as an important criterion. Based on the process outlined above, 12 criteria were identified: Familiarity [3,55], Likeability (executive proposed), Attitude [55,56], Expression [3,55-57], Emotion (executive proposed), Response [55-57], Experience [55], Cost (executive proposed), Match (executive proposed), YouTube (executive proposed), Facebook (executive proposed), and Instagram (executive proposed). Based on Chen et al. [55], we consulted four senior executives (a deputy general manager and three managers of a program department) who were experienced in television program production for at least 25 years to classify 12 important criteria into four perspectives (Person, Profession, Program, and Promotion), showing in Table 3. Three hosts are alternatives in a case company. Therefore, the hierarchy was developed.

Table 2. The results of the fuzzy Delphi method.

\begin{tabular}{cc}
\hline Criteria & Geometric Mean \\
\hline Expertise & 6.4007 \\
Experience & 7.4466 \\
Education & 6.1803 \\
Appearance & 6.2223 \\
Ability to follow orders & 6.1803 \\
Confidence & 6.1672 \\
Expression & 7.2107 \\
Response & 7.2381 \\
Desire of performance & 5.8800 \\
Living experience & 5.6806 \\
Familiarity & 7.4449 \\
Creativity & 6.2953 \\
Adaptation to company & 5.3741 \\
Teamwork & 6.2518 \\
Interpersonal skill & 6.1682 \\
Adaptation to environment & 6.0776 \\
Attitude & 7.4172 \\
Language & 5.6714 \\
Likeability & 7.4570 \\
Emotion & 7.3461 \\
Cost & 7.4939 \\
Match & 7.9214 \\
Facebook (number of posts shared) & 7.8596 \\
Instagram & 6.9637 \\
Facebook (number of fans) & 7.3322 \\
YouTube (number of views) & 7.0743 \\
\hline & 7.6511 \\
\hline
\end{tabular}


Table 3. Definitions and contributors to the selection criteria.

\begin{tabular}{|c|c|c|c|}
\hline Perspective & Criteria & Definition & Contributors \\
\hline \multirow{3}{*}{ Person } & $C_{1}$ : Familiarity & Familiarity to the target audience. & {$[3,55]$} \\
\hline & $C_{2}$ : Likeability & Likeability to the target audience. & Executive proposed \\
\hline & $C_{3}:$ Attitude & Conscientious toward the work. & {$[55,56]$} \\
\hline \multirow{3}{*}{ Profession } & $C_{4}$ : Expression & Expression ability. & {$[3,55-57]$} \\
\hline & $C_{5}:$ Emotion & Emotional steadiness. & Executive proposed \\
\hline & $C_{6}:$ Response & React appropriately to the emergency. & {$[55-57]$} \\
\hline \multirow{3}{*}{ Program } & $C_{7}:$ Experience & Hosting experience. & {$[55]$} \\
\hline & $C_{8}:$ Cost & Cost of acquiring the host. & Executive proposed \\
\hline & $C_{9}:$ Match & Match between host and program. & Executive proposed \\
\hline \multirow{3}{*}{ Promotion } & $C_{10}:$ YouTube & Views of the host's YouTube channel. & Executive proposed \\
\hline & $C_{11}:$ Facebook & $\begin{array}{l}\text { The number of people in the host's Facebook } \\
\text { fan page. }\end{array}$ & Executive proposed \\
\hline & $C_{12}:$ Instagram & The number of fans in the host's Instagram. & Executive proposed \\
\hline
\end{tabular}

The decision-making group included three senior managers of a television station. The data were collected via face-to-face interview. By DEMATEL, the initial direct-relation matrix and total-influence relation matrix of perspectives were assessed, showing in Tables 4 and 5. 9 present the threshold values that were determined by the decision-making committee. Based on this process, the relations among perspectives were created, as shown in Figure 3. The hierarchy with a causal relationship to select the optimal variety show hosts for television stations is presented in Figure 4.

Table 4. The initial direct-relation matrix of perspectives.

\begin{tabular}{ccccc}
\hline Perspectives & Person & Profession & Program & Promotion \\
\hline Person & 0.000 & 4.000 & 3.000 & 3.333 \\
Profession & 4.000 & 0.000 & 3.333 & 3.000 \\
Program & 3.000 & 3.333 & 0.000 & 3.000 \\
Promotion & 4.000 & 3.333 & 3.000 & 0.000 \\
\hline
\end{tabular}

Table 5. The total-influence relation matrix of perspectives.

\begin{tabular}{ccccc}
\hline Perspectives & Person & Profession & Program & Promotion \\
\hline Person & 11.4600 & 11.4977 & 10.3333 & 10.3574 \\
Profession & 11.7174 & 11.1985 & 10.3333 & 10.3213 \\
Program & 10.8056 & 10.6011 & 9.3333 & 9.5634 \\
Promotion & 11.7402 & 11.4635 & 10.3333 & 10.1153 \\
\hline
\end{tabular}

The threshold value is 9.0000 .

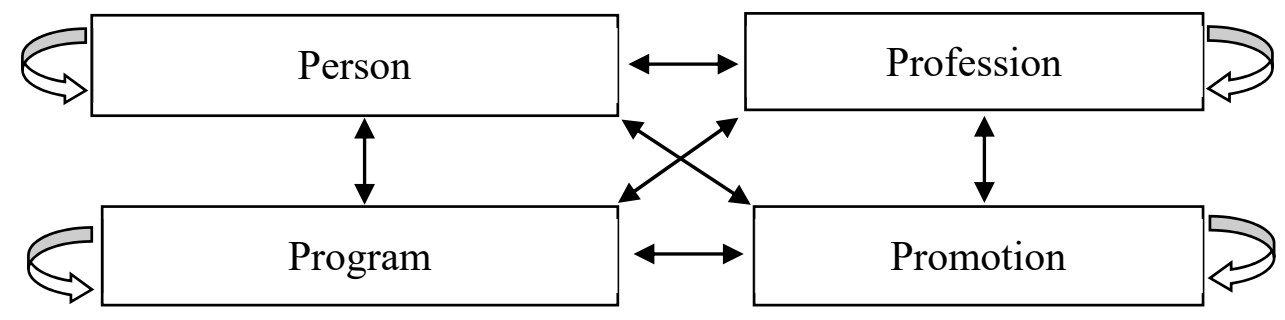

Figure 3. The interdependencies among perspectives. 


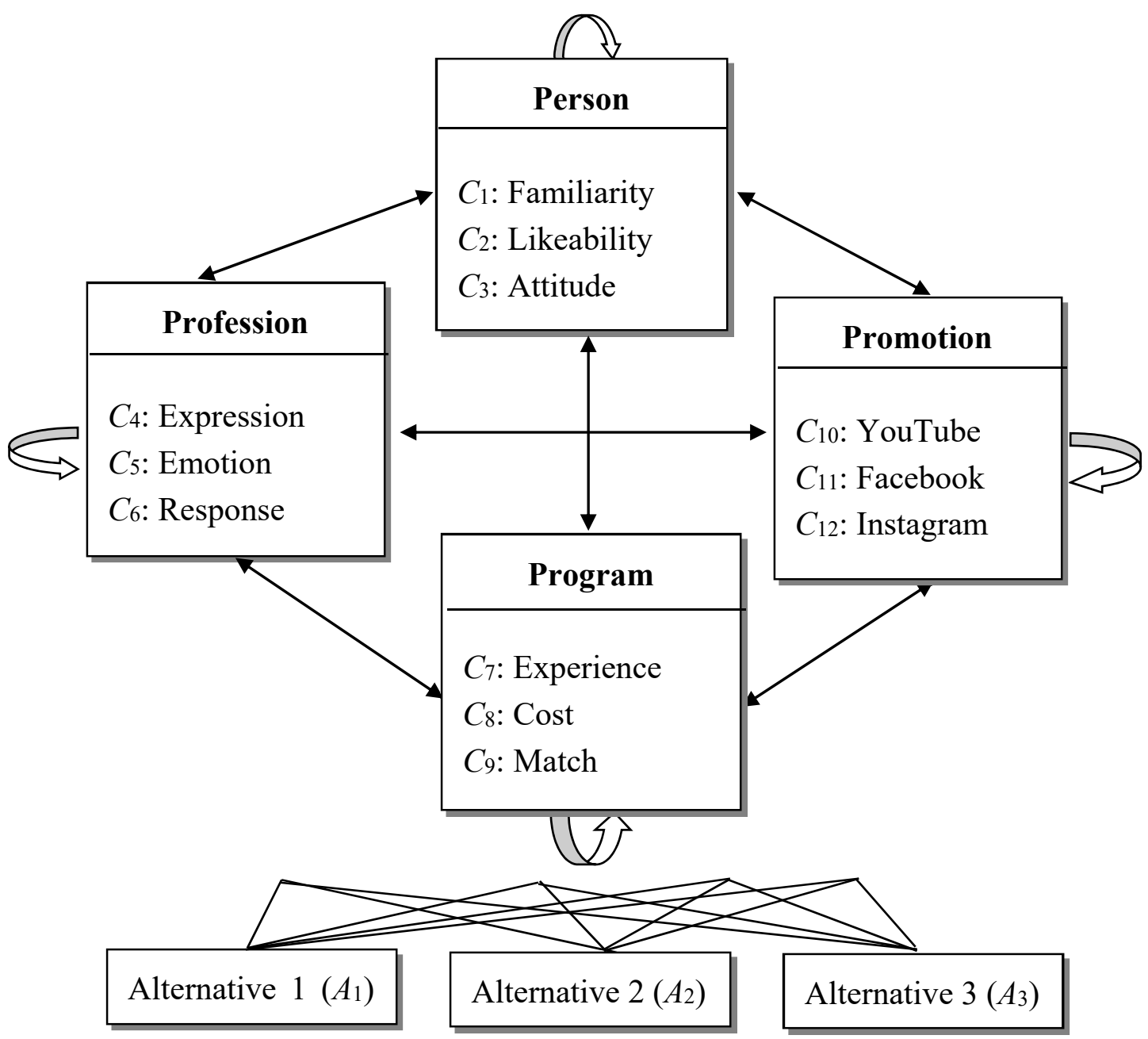

Figure 4. Hierarchy with a causal relationship to select the optimal hosts for television variety shows.

\subsection{Complete Pairwise Comparison}

Every perspective's and criterion's priority weight can be depicted based on interdependencies. The pairwise comparison matrices of perspectives are presented in Appendix A. As for criteria, an example of a pairwise comparison within the Profession perspective concerning Familiarity is also shown in Appendix A.

\subsection{Solve the Supermatrix}

Following Step 2, an unweighted supermatrix is formed, as shown in Appendix B. Then, the unweighted supermatrix is converted into a weighted supermatrix by multiplying the priority weights from the perspectives. At last, the weighted supermatrix can converge into a stable supermatrix (limiting supermatrix). The global priorities weight of the criteria is presented in Appendix B.

\subsection{Build a Normalized and a Weighted Evaluation Matrix}

Three managers established the evaluation matrix by comparing three alternatives concerning each criterion on the basis of a 9-point Likert scale. In Equation (8), we obtain the normalized evaluation matrix, as shown in Table 6. The weighted evaluation matrix is shown in Table 7. 
Table 6. The normalized evaluation matrix.

\begin{tabular}{ccccccccccccc}
\hline & $C_{\mathbf{1}}$ & $C_{\mathbf{2}}$ & $C_{\mathbf{3}}$ & $C_{\mathbf{4}}$ & $C_{\mathbf{5}}$ & $C_{\mathbf{6}}$ & $C_{\mathbf{7}}$ & $C_{\mathbf{8}}$ & $C_{\mathbf{9}}$ & $C_{\mathbf{1 0}}$ & $C_{\mathbf{1 1}}$ & $C_{\mathbf{1 2}}$ \\
\hline$A_{1}$ & 0.5972 & 0.6466 & 0.6420 & 0.6099 & 0.6191 & 0.6206 & 0.6025 & 0.5774 & 0.6041 & 0.7665 & 0.7786 & 0.7647 \\
$A_{2}$ & 0.4708 & 0.5084 & 0.5541 & 0.5365 & 0.5408 & 0.5123 & 0.5235 & 0.5774 & 0.5489 & 0.4707 & 0.4438 & 0.4557 \\
$A_{3}$ & 0.6494 & 0.5687 & 0.5300 & 0.5833 & 0.5694 & 0.5936 & 0.6025 & 0.5774 & 0.5778 & 0.4369 & 0.4438 & 0.4557 \\
\hline
\end{tabular}

Identify PIS and NIS

$A^{*}=(0.0659,0.0496,0.0740,0.0645,0.0437,0.0619,0.0515,0.0346,0.0563,0.0538,0.0347,0.0590)$,

$A^{-}=(0.0478,0.0390,0.0610,0.0567,0.0382,0.0511,0.0448,0.0346,0.0511,0.0307,0.0198,0.0352)$.

Table 7. The weighted evaluation matrix.

\begin{tabular}{ccccccccccccc}
\hline & $C_{\mathbf{1}}$ & $C_{\mathbf{2}}$ & $C_{\mathbf{3}}$ & $C_{\mathbf{4}}$ & $C_{\mathbf{5}}$ & $C_{\mathbf{6}}$ & $C_{\mathbf{7}}$ & $C_{\mathbf{8}}$ & $\boldsymbol{C}_{\mathbf{9}}$ & $C_{\mathbf{1 0}}$ & $C_{\mathbf{1 1}}$ & $C_{\mathbf{1 2}}$ \\
\hline$A_{1}$ & 0.0606 & 0.0496 & 0.0740 & 0.0645 & 0.0437 & 0.0619 & 0.0515 & 0.0346 & 0.0563 & 0.0538 & 0.0347 & 0.0590 \\
$A_{2}$ & 0.0478 & 0.0390 & 0.0638 & 0.0567 & 0.0382 & 0.0511 & 0.0448 & 0.0346 & 0.0511 & 0.0331 & 0.0198 & 0.0352 \\
$A_{3}$ & 0.0659 & 0.0436 & 0.0610 & 0.0617 & 0.0402 & 0.0592 & 0.0515 & 0.0346 & 0.0538 & 0.0307 & 0.0198 & 0.0352 \\
\hline
\end{tabular}

\subsection{Rank the Alternative}

The preferred host is selected based on Table 8. The ranking for the appropriate host is $A_{1}, A_{3}$, and $A_{2}$. The case company selected the host per our suggestion.

Table 8. The final ranking of alternatives.

\begin{tabular}{ccccc}
\hline & $S_{i}^{*}$ & $S_{i}^{-}$ & $C_{i}^{*}$ & Rank \\
\hline$A_{1}$ & 0.0053 & 0.0453 & 0.8953 & 1 \\
$A_{2}$ & 0.0452 & 0.0037 & 0.0747 & 3 \\
$A_{3}$ & 0.0395 & 0.0223 & 0.3607 & 2 \\
\hline
\end{tabular}

A sensitivity analysis was carried out in this paper. Based on Ziemba [58] and Ziemba et al. [59], the stability intervals of ANP-TOPSIS and AHP-TOPSIS are presented in Tables 9 and 10. The rankings obtained by ANP-TOPSIS and AHP-TOPSIS are quite stable.

Table 9. The stability intervals of ANP-TOPSIS.

\begin{tabular}{ccccc}
\hline & \multirow{2}{*}{ Weights From ANP } & \multicolumn{3}{c}{ ANP-TOPSIS } \\
\cline { 3 - 5 } & & Min & Max & Range \\
\hline$C_{1}$ & 0.10 & 0.00 & 0.32 & 0.32 \\
$C_{2}$ & 0.08 & 0.00 & 0.57 & 0.57 \\
$C_{3}$ & 0.12 & 0.00 & 0.45 & 0.45 \\
$C_{4}$ & 0.11 & 0.00 & 0.55 & 0.55 \\
$C_{5}$ & 0.07 & 0.00 & 0.51 & 0.51 \\
$C_{6}$ & 0.10 & 0.00 & 0.54 & 0.54 \\
$C_{7}$ & 0.09 & 0.00 & 0.53 & 0.53 \\
$C_{8}$ & 0.06 & 0.00 & 0.50 & 0.50 \\
$C_{9}$ & 0.09 & 0.00 & 0.53 & 0.53 \\
$C_{10}$ & 0.07 & 0.00 & 0.40 & 0.40 \\
$C_{11}$ & 0.04 & 0.00 & 0.48 & 0.48 \\
$C_{12}$ & 0.08 & 0.00 & 0.52 & 0.52 \\
\hline
\end{tabular}


Table 10. The stability intervals of AHP-TOPSIS.

\begin{tabular}{llccc}
\hline & \multirow{2}{*}{ Weights From AHP } & \multicolumn{3}{c}{ AHP-TOPSIS } \\
\cline { 3 - 5 } & & Min & Max & Range \\
\hline$C_{1}$ & 0.05 & 0.00 & 0.38 & 0.38 \\
$C_{2}$ & 0.03 & 0.00 & 0.36 & 0.36 \\
$C_{3}$ & 0.09 & 0.00 & 0.31 & 0.31 \\
$C_{4}$ & 0.12 & 0.00 & 0.45 & 0.45 \\
$C_{5}$ & 0.07 & 0.00 & 0.40 & 0.40 \\
$C_{6}$ & 0.12 & 0.00 & 0.45 & 0.45 \\
$C_{7}$ & 0.10 & 0.00 & 0.43 & 0.43 \\
$C_{8}$ & 0.05 & 0.00 & 0.38 & 0.38 \\
$C_{9}$ & 0.10 & 0.00 & 0.43 & 0.43 \\
$C_{10}$ & 0.13 & 0.00 & 0.24 & 0.24 \\
$C_{11}$ & 0.06 & 0.00 & 0.39 & 0.39 \\
$C_{12}$ & 0.06 & 0.00 & 0.39 & 0.39 \\
\hline
\end{tabular}

Further, Table 11 showed the comparative analysis for comparing the ranking of alternatives with AHP, AHP and TOPSIS, and ANP to test the robustness of the results. The results and our proposed model are the same. However, the results also confirmed the effectiveness of this study. The proposed model and the three applied techniques (AHP, AHP and TOPSIS, and ANP) all agreed that $A_{1}$ is the best and $A_{2}$ is the worst.

Table 11. Comparative analysis based on different approaches.

\begin{tabular}{cc}
\hline Approach & Rank \\
\hline AHP & $A_{1}>A_{3}>A_{2}$ \\
AHP and TOPSIS & $A_{1}>A_{3}>A_{2}$ \\
ANP & $A_{1}>A_{3}>A_{2}$ \\
\hline
\end{tabular}

\section{Conclusions}

Decision making is a core competency of management that determines the success or failure of a company. In today's highly competitive global economy, trade-offs must be made between many conflicting goals; however, to do so, conventional single criteria decision-making methods are insufficient. Consequently, MCDM approaches have been employed in many fields. The personnel selection problem, which is a significant topic for organizations' success, belongs to an MCDM problem. MCDM is a basic part of our lives. Therefore, many MCDM approaches were herein proposed. A hybrid MCDM model based on the fuzzy Delphi method, DEMATEL, ANP, and TOPSIS for the selection of variety show hosts was developed in this paper.

There is no study to date that considers the MCDM approach for variety show host selection. Additionally, this study also examined the selection of hosts in the context of social media competition. From previous studies and consultations with senior executives of television stations, the selection criteria for variety show hosts were gathered. By the fuzzy Delphi method, the 12 criteria were distinguished, including Familiarity, Likeability, Attitude, Expression, Emotion, Response, Experience, Cost, Match, YouTube, Facebook, and Instagram. The choice of selection criteria is important to successful decision-making support. Firstly, we contributed to defining the criteria necessary for variety show hosts. Second, DEMATEL was applied to verify interdependencies between the perspectives. Based on the result of DEMATEL, the weighting of perspectives and criteria were obtained via ANP. TOPSIS was used to rank the television variety show hosts. TOPSIS removed procedures that are performed in ANP, enabling us to obtain a decisive conclusion in a shorter time. We not only handled the cause-effect relationships between each perspective but also generated more valuable information for television station managers to make decisions. To validate the effectiveness of the proposed model, 
a deputy general manager of the case company was interviewed. The performance of the host and the ratings of the program are better than expected.

Regarding future research, the other MCDM techniques can be used in this topic. To cope with uncertainty or fuzziness in the decision-making process, fuzzy DEMATEL, fuzzy ANP, or fuzzy TOPSIS can be utilized in this model. This study examined 12 criteria for the selection of variety show hosts. Future studies are advised to accompany more criteria, making the model more comprehensive. Moreover, further studies can be accomplished in other countries to determine whether the model remains consistent. The case company only selected $A_{1}$ as their variety show host. Through the interview, the performance of $A_{1}$ and the ratings of the program are better than expected. However, we are limited to compare the performance of the three alternatives, practically.

Author Contributions: Conceptualization, K.-L.C.; methodology, L.-C.W., K.-L.C., and S.-K.L.; software, K.-L.C.; validation, L.-C.W., K.-L.C., and S.-K.L.; formal analysis, K.-L.C.; investigation, K.-L.C.; resources, L.-C.W. and S.-K.L.; data curation, K.-L.C.; writing-original draft preparation, K.-L.C.; writing-review and editing, L.-C.W., K.-L.C. and S.-K.L. All authors have read and agreed to the published version of the manuscript.

Funding: This research received no external funding.

Conflicts of Interest: The authors declare no conflict of interest.

\section{Appendix A. The Pairwise Comparison Matrices}

Table A1. The interdependent matrix of the perspectives concerning the 'Person' perspective.

\begin{tabular}{cccccc}
\hline & Person & Profession & Program & Promotion & Priority Weights \\
\cline { 2 - 5 } & & \multicolumn{4}{c}{$\lambda_{\max }=\mathbf{4 . 1 0 9 2 , C R}=\mathbf{0 . 0 3 6 8}$} \\
\hline Person & 1.0000 & 1.5874 & 0.8355 & 1.4736 & 0.2874 \\
Profession & 0.6300 & 1.0000 & 1.4422 & 2.0801 & 0.2850 \\
Program & 1.1968 & 0.6934 & 1.0000 & 1.8171 & 0.2694 \\
Promotion & 0.6786 & 0.4807 & 0.5503 & 1.0000 & 0.1582 \\
\hline
\end{tabular}

Table A2. The interdependent matrix of the perspectives concerning the 'Profession' perspective.

\begin{tabular}{cccccc}
\hline & Person & Profession & Program & Promotion & Priority Weights \\
\cline { 2 - 5 } & & \multicolumn{4}{c}{$\lambda_{\max }=\mathbf{4 . 0 1 7 5 , C R}=\mathbf{0 . 0 0 5 9}$} \\
\hline Person & 1.0000 & 0.5754 & 0.5754 & 0.6114 & 0.1631 \\
Profession & 1.7380 & 1.0000 & 1.4422 & 1.1447 & 0.3164 \\
Program & 1.7380 & 0.6934 & 1.0000 & 1.1447 & 0.2635 \\
Promotion & 1.6355 & 0.8736 & 0.8736 & 1.0000 & 0.2570 \\
\hline
\end{tabular}

Table A3. The interdependent matrix of the perspectives concerning the 'Program' perspective.

\begin{tabular}{cccccc}
\hline & Person & Profession & Program & Promotion & Priority Weights \\
\cline { 2 - 5 } & & \multicolumn{3}{c}{$\lambda_{\max }=\mathbf{4 . 0 2 2 6}, \mathbf{C R}=\mathbf{0 . 0 0 7 6}$} \\
\hline Person & 1.0000 & 0.9565 & 1.0455 & 1.1006 & 0.2535 \\
Profession & 1.0455 & 1.0000 & 1.4422 & 1.4422 & 0.3005 \\
Program & 0.9565 & 0.6934 & 1.0000 & 1.4422 & 0.2448 \\
Promotion & 0.9086 & 0.6934 & 0.6934 & 1.0000 & 0.2012 \\
\hline
\end{tabular}


Table A4. The interdependent matrix of the perspectives concerning the 'Promotion' perspective.

\begin{tabular}{cccccc}
\hline & Person & Profession & Program & Promotion & Priority Weights \\
\cline { 2 - 5 } & & \multicolumn{3}{c}{$\lambda_{\max }=\mathbf{4 . 0 3 5 9 ,} \mathbf{C R}=\mathbf{0 . 0 1 2 1}$} \\
\hline Person & 1.0000 & 3.8259 & 3.4760 & 3.3019 & 0.5393 \\
Profession & 0.2614 & 1.0000 & 1.4422 & 1.2599 & 0.1739 \\
Program & 0.2877 & 0.6934 & 1.0000 & 1.2599 & 0.1483 \\
Promotion & 0.3029 & 0.7937 & 0.7937 & 1.0000 & 0.1385 \\
\hline
\end{tabular}

Table A5. The interdependent matrix within the Profession perspective concerning the 'Familiarity' criteria.

\begin{tabular}{ccccc}
\hline & Expression & Emotion & Response & Priority Weights \\
\cline { 2 - 4 } & \multicolumn{3}{c}{$\lambda_{\max }=\mathbf{3 . 0 1 3 6 , \mathbf { C R } = \mathbf { 0 . 0 1 0 3 }}$} \\
\hline Expression & 1.0000 & 0.5228 & 0.4055 & 0.1871 \\
\hline Emotion & 1.9129 & 1.0000 & 1.1006 & 0.4022 \\
\hline Response & 2.4662 & 0.9086 & 1.0000 & 0.4107 \\
\hline
\end{tabular}

\section{Appendix B. The Unweighted, Weighted, and Limiting Supermatrices}

Table A6. The unweighted supermatrix.

\begin{tabular}{ccccccccccccc}
\hline & $\boldsymbol{C}_{\mathbf{1}}$ & $\boldsymbol{C}_{\mathbf{2}}$ & $\boldsymbol{C}_{\mathbf{3}}$ & $\boldsymbol{C}_{\mathbf{4}}$ & $\boldsymbol{C}_{\mathbf{5}}$ & $\boldsymbol{C}_{\mathbf{6}}$ & $\boldsymbol{C}_{\mathbf{7}}$ & $\boldsymbol{C}_{\mathbf{8}}$ & $\boldsymbol{C}_{\mathbf{9}}$ & $\boldsymbol{C}_{\mathbf{1 0}}$ & $\boldsymbol{C}_{\mathbf{1 1}}$ & $\boldsymbol{C}_{\mathbf{1 2}}$ \\
\hline$C_{1}$ & 0.2365 & 0.3921 & 0.3921 & 0.5098 & 0.2072 & 0.3869 & 0.2781 & 0.3856 & 0.4808 & 0.2920 & 0.3390 & 0.3143 \\
$C_{2}$ & 0.4035 & 0.2158 & 0.2158 & 0.2451 & 0.3964 & 0.2262 & 0.2475 & 0.2210 & 0.2696 & 0.3054 & 0.2195 & 0.2059 \\
$C_{3}$ & 0.3599 & 0.3921 & 0.3921 & 0.2451 & 0.3964 & 0.3869 & 0.4745 & 0.3935 & 0.2496 & 0.4026 & 0.4416 & 0.4798 \\
$C_{4}$ & 0.1871 & 0.4225 & 0.5294 & 0.5091 & 0.4736 & 0.3014 & 0.3856 & 0.2395 & 0.4600 & 0.2479 & 0.2836 & 0.3143 \\
$C_{5}$ & 0.4022 & 0.2153 & 0.1840 & 0.2643 & 0.3524 & 0.1727 & 0.2210 & 0.3802 & 0.2211 & 0.2593 & 0.1836 & 0.2059 \\
$C_{6}$ & 0.4107 & 0.3622 & 0.2866 & 0.2266 & 0.1739 & 0.5259 & 0.3935 & 0.3802 & 0.3189 & 0.4929 & 0.5328 & 0.4798 \\
$C_{7}$ & 0.1698 & 0.4483 & 0.3316 & 0.5098 & 0.4889 & 0.2438 & 0.3971 & 0.3333 & 0.4193 & 0.2920 & 0.3390 & 0.3143 \\
$C_{8}$ & 0.4454 & 0.1958 & 0.1282 & 0.2451 & 0.2556 & 0.2525 & 0.2067 & 0.3333 & 0.2351 & 0.3054 & 0.2195 & 0.2059 \\
$C_{9}$ & 0.3848 & 0.3558 & 0.5403 & 0.2451 & 0.2556 & 0.5037 & 0.3962 & 0.3333 & 0.3456 & 0.4026 & 0.4416 & 0.4798 \\
$C_{10}$ & 0.4099 & 0.3862 & 0.4587 & 0.4343 & 0.1617 & 0.2940 & 0.2918 & 0.3333 & 0.4457 & 0.3512 & 0.3390 & 0.5098 \\
$C_{11}$ & 0.2156 & 0.1968 & 0.2524 & 0.2088 & 0.3093 & 0.1719 & 0.1672 & 0.3333 & 0.2142 & 0.3584 & 0.2195 & 0.2451 \\
$C_{12}$ & 0.3745 & 0.4171 & 0.2889 & 0.3570 & 0.5290 & 0.5341 & 0.5410 & 0.3333 & 0.3401 & 0.2903 & 0.4416 & 0.2451 \\
\hline
\end{tabular}

Table A7. The weighted supermatrix.

\begin{tabular}{|c|c|c|c|c|c|c|c|c|c|c|c|c|}
\hline & $C_{1}$ & $C_{2}$ & $C_{3}$ & $C_{4}$ & $C_{5}$ & $C_{6}$ & $C_{7}$ & $C_{8}$ & $C_{9}$ & $C_{10}$ & $C_{11}$ & $C_{12}$ \\
\hline$C_{1}$ & 0.0680 & 0.1127 & 0.1127 & 0.0831 & 0.0338 & 0.0631 & 0.0705 & 0.0977 & 0.1219 & 0.1575 & 0.1828 & 0.1695 \\
\hline$C_{2}$ & 0.1160 & 0.0620 & 0.0620 & 0.0400 & 0.0646 & 0.0369 & 0.0627 & 0.0560 & 0.0683 & 0.1647 & 0.1184 & 0.1110 \\
\hline$C_{3}$ & 0.1034 & 0.1127 & 0.1127 & 0.0400 & 0.0646 & 0.0631 & 0.1203 & 0.0997 & 0.0633 & 0.2171 & 0.2381 & 0.2587 \\
\hline$C_{4}$ & 0.0533 & 0.1204 & 0.1509 & 0.1611 & 0.1499 & 0.0954 & 0.1159 & 0.0720 & 0.1382 & 0.0431 & 0.0493 & 0.0547 \\
\hline$C_{5}$ & 0.1146 & 0.0614 & 0.0524 & 0.0836 & 0.1115 & 0.0547 & 0.0664 & 0.1143 & 0.0665 & 0.0451 & 0.0319 & 0.0358 \\
\hline$C_{6}$ & 0.1170 & 0.1032 & 0.0817 & 0.0717 & 0.0550 & 0.1664 & 0.1183 & 0.1143 & 0.0959 & 0.0857 & 0.0927 & 0.0834 \\
\hline$C_{7}$ & 0.0457 & 0.1208 & 0.0893 & 0.1343 & 0.1288 & 0.0642 & 0.0972 & 0.0816 & 0.1026 & 0.0433 & 0.0503 & 0.0466 \\
\hline$C_{8}$ & 0.1200 & 0.0527 & 0.0345 & 0.0646 & 0.0673 & 0.0665 & 0.0506 & 0.0816 & 0.0576 & 0.0453 & 0.0326 & 0.0305 \\
\hline$C_{9}$ & 0.1036 & 0.0958 & 0.1455 & 0.0646 & 0.0673 & 0.1327 & 0.0970 & 0.0816 & 0.0846 & 0.0597 & 0.0655 & 0.0712 \\
\hline$C_{10}$ & 0.0648 & 0.0611 & 0.0726 & 0.1116 & 0.0416 & 0.0755 & 0.0587 & 0.0671 & 0.0897 & 0.0486 & 0.0469 & 0.0706 \\
\hline$C_{11}$ & 0.0341 & 0.0311 & 0.0399 & 0.0536 & 0.0795 & 0.0442 & 0.0336 & 0.0671 & 0.0431 & 0.0496 & 0.0304 & 0.0339 \\
\hline$C_{12}$ & 0.0593 & 0.0660 & 0.0457 & 0.0917 & 0.1359 & 0.1373 & 0.1089 & 0.0671 & 0.0684 & 0.0402 & 0.0611 & 0.0339 \\
\hline
\end{tabular}


Table A8. The limiting supermatrix.

\begin{tabular}{ccccccccccccc}
\hline & $C_{\mathbf{1}}$ & $\boldsymbol{C}_{\mathbf{2}}$ & $\boldsymbol{C}_{\mathbf{3}}$ & $\boldsymbol{C}_{\mathbf{4}}$ & $\boldsymbol{C}_{\mathbf{5}}$ & $\boldsymbol{C}_{\mathbf{6}}$ & $\boldsymbol{C}_{\mathbf{7}}$ & $\boldsymbol{C}_{\mathbf{8}}$ & $\boldsymbol{C}_{\mathbf{9}}$ & $\boldsymbol{C}_{\mathbf{1 0}}$ & $\boldsymbol{C}_{\mathbf{1 1}}$ & $\boldsymbol{C}_{\mathbf{1 2}}$ \\
\hline$C_{1}$ & 0.1015 & 0.1015 & 0.1015 & 0.1015 & 0.1015 & 0.1015 & 0.1015 & 0.1015 & 0.1015 & 0.1015 & 0.1015 & 0.1015 \\
$C_{2}$ & 0.0766 & 0.0766 & 0.0766 & 0.0766 & 0.0766 & 0.0766 & 0.0766 & 0.0766 & 0.0766 & 0.0766 & 0.0766 & 0.0766 \\
$C_{3}$ & 0.1152 & 0.1152 & 0.1152 & 0.1152 & 0.1152 & 0.1152 & 0.1152 & 0.1152 & 0.1152 & 0.1152 & 0.1152 & 0.1152 \\
$C_{4}$ & 0.1057 & 0.1057 & 0.1057 & 0.1057 & 0.1057 & 0.1057 & 0.1057 & 0.1057 & 0.1057 & 0.1057 & 0.1057 & 0.1057 \\
$C_{5}$ & 0.0706 & 0.0706 & 0.0706 & 0.0706 & 0.0706 & 0.0706 & 0.0706 & 0.0706 & 0.0706 & 0.0706 & 0.0706 & 0.0706 \\
$C_{6}$ & 0.0998 & 0.0998 & 0.0998 & 0.0998 & 0.0998 & 0.0998 & 0.0998 & 0.0998 & 0.0998 & 0.0998 & 0.0998 & 0.0998 \\
$C_{7}$ & 0.0855 & 0.0855 & 0.0855 & 0.0855 & 0.0855 & 0.0855 & 0.0855 & 0.0855 & 0.0855 & 0.0855 & 0.0855 & 0.0855 \\
$C_{8}$ & 0.0600 & 0.0600 & 0.0600 & 0.0600 & 0.0600 & 0.0600 & 0.0600 & 0.0600 & 0.0600 & 0.0600 & 0.0600 & 0.0600 \\
$C_{9}$ & 0.0931 & 0.0931 & 0.0931 & 0.0931 & 0.0931 & 0.0931 & 0.0931 & 0.0931 & 0.0931 & 0.0931 & 0.0931 & 0.0931 \\
$C_{10}$ & 0.0702 & 0.0702 & 0.0702 & 0.0702 & 0.0702 & 0.0702 & 0.0702 & 0.0702 & 0.0702 & 0.0702 & 0.0702 & 0.0702 \\
$C_{11}$ & 0.0445 & 0.0445 & 0.0445 & 0.0445 & 0.0445 & 0.0445 & 0.0445 & 0.0445 & 0.0445 & 0.0445 & 0.0445 & 0.0445 \\
$C_{12}$ & 0.0772 & 0.0772 & 0.0772 & 0.0772 & 0.0772 & 0.0772 & 0.0772 & 0.0772 & 0.0772 & 0.0772 & 0.0772 & 0.0772 \\
\hline
\end{tabular}

\section{References}

1. Jia, C.P. On glamour of TV anchors. J. Qinghai Norm. Univ. (Philos. Soc. Sci.) 2011, 33, 150-152.

2. Aznárez-Mauleón, M. An approach to the host's discursive style in Spanish “testimony” talk shows. J. Pragmat. 2013, 45, 50-73. [CrossRef]

3. Wang, D. Research about the hosts of character-type talk show. J. Commun. 2015, 3, 39-44.

4. Jin, S.V. “Celebrity 2.0 and beyond!” effects of Facebook profile sources on social networking advertising. Comput. Hum. Behav. 2018, 79, 154-168. [CrossRef]

5. Shepherd, H.; Lane, J. In the mix: Social integration and social media adoption. Soc. Sci. Res. 2019, 82, 1-17. [CrossRef] [PubMed]

6. Hwang, K.; Zhang, Q. Influence of parasocial relationship between digital celebrities and their followers on followers' purchase and electronic word-of-mouth intentions, and persuasion knowledge. Comput. Hum. Behav. 2018, 87, 155-173. [CrossRef]

7. Pérez-Bustamante Ilander, G.O.; Marques, C.S.E.; Jalali, M.S.; Ferreira, F.A.F. The impact of continuous training in small and medium enterprises: Lessons from an industrial case analysis. J. Bus. Econ. Manag. 2016, 17, 234-250. [CrossRef]

8. Wen, T.C.; Chang, K.H.; Lai, H.H. Improving personnel selection by combining the minimal variance OWA operator and IPA. J. Intell. Fuzzy Syst. 2018, 35, 6229-6239. [CrossRef]

9. Gonçalves, J.M.; Ferreira, F.A.F.; Ferreira, J.J.M.; Farinha, L.M.C. A multiple criteria group decision-making approach for the assessment of small and medium-sized enterprise competitiveness. Manag. Decis. 2019, 57, 480-500. [CrossRef]

10. Chang, P.L.; Hsu, C.W. An assessment model for hydrogen fuel cell applications: Fuzzy Delphi approach. Int. J. Soc. Sci. Humanit. 2011, 1, 218-223. [CrossRef]

11. Chang, P.L.; Hsu, C.W.; Chang, P.C. Fuzzy Delphi method for evaluating hydrogen production technologies. Int. J. Hydrogen Energy 2011, 36, 14172-14179. [CrossRef]

12. López-Ospina, H.; Quezada, L.E.; Barros-Castro, R.A.; Gonzalez, M.A.; Palominos, P.I. A method for designing strategy maps using DEMATEL and linear programming. Manag. Decis. 2017, 55, 1802-1823. [CrossRef]

13. Awang, A.; Aizam, N.A.H.; Abdullah, L. An integrated decision-making method based on neutrosophic numbers for investigating factors of coastal erosion. Symmetry 2019, 11, 328. [CrossRef]

14. Zhang, J. Evaluating regional low-carbon tourism strategies using the fuzzy Delphi- analytic network process approach. J. Clean. Prod. 2017, 141, 409-419. [CrossRef]

15. Ballı, S.; Korukoğlu, S. Development of a fuzzy decision support framework for complex multi-attribute decision problems: A case study for the selection of skilful basketball players. Expert Syst. 2014, 31, 56-69. [CrossRef]

16. Dadelo, S.; Turskis, Z.; Zavadskas, E.K.; Dadeliene, R. Multi-criteria assessment and ranking system of sport team formation based on objective-measured values of criteria set. Expert Syst. Appl. 2014, 41, 6106-6113. [CrossRef] 
17. Keršulienè, V.; Turskis, Z. A hybrid linguistic fuzzy multiple criteria group selection of a chief accounting officer. J. Bus. Econ. Manag. 2014, 15, 232-252. [CrossRef]

18. Chang, K.L. The use of a hybrid MCDM model for public relations personnel selection. Informatica 2015, 26, 389-406. [CrossRef]

19. Chang, K.L.; Liao, S.K.; Chen, Y.C. A hybrid MCDM approach for Taiwanese tour guides selection. J. Mult.-Valued Log. Soft Comput. 2015, 25, 605-621.

20. Karabasevic, D.; Stanujkic, D.; Urosevic, S.; Maksimovic, M. Selection of candidates in the mining industry based on the application of the SWARA and the MULTIMOORA methods. Acta Montan. Slovaca 2015, 20, 116-124.

21. Sang, X.; Liu, X.; Qin, J. An analytical solution to fuzzy TOPSIS and its application in personnel selection for knowledge-intensive enterprise. Appl. Soft Comput. 2015, 30, 190-204. [CrossRef]

22. Asuquo, D.E.; Onuodu, F.E. A fuzzy AHP model for selection of university academic staff. Int. J. Comput. Appl. 2016, 141, 19-26.

23. Erdem, M.B. A fuzzy analytical hierarchy process application in personnel selection in IT companies: A case study in a spin-off company. Acta Phys. Pol. A 2016, 130, 331-334. [CrossRef]

24. Karabasevic, D.; Zavadskas, E.K.; Turskis, Z.; Stanujkic, D. The framework for the selection of personnel based on the SWARA and ARAS methods under uncertainties. Informatica 2016, 27, 49-65. [CrossRef]

25. Kosareva, N.; Zavadskas, E.K.; Krylovas, A.; Dadelo, S. Personnel ranking and selection problem solution by application of KEMIRA method. Int. J. Comput. Commun. Control 2016, 11, 51-66. [CrossRef]

26. Stanujkic, D.; Karabasevic, D.; Zavadskas, E.K. A new approach for selecting alternatives based on the adapted weighted sum and the SWARA methods: A case of personnel selection. Econ. Comput. Econ. Cybern. Stud. Res. 2017, 51, 39-56.

27. Urosevic, S.; Karabasevic, D.; Stanujkic, D.; Maksimovic, M. An approach to personnel selection in the tourism industry based on the SWARA and the WASPAS methods. Econ. Comput. Econ. Cybern. Stud. Res. 2017, 51, 75-88.

28. Deliktas, D.; Üstun, Ö. Multiple criteria decision making approach for industrial engineer selection using fuzzy AHP-fuzzy TOPSIS. Anadolu Univ. J. Sci. Technol. A-Appl. Sci. Eng. 2018, 19, 58-82. [CrossRef]

29. Ji, P.; Zhang, H.; Wang, J. A projection-based TODIM method under multi-valued neutrosophic environments and its application in personnel selection. Neural Comput. Appl. 2018, 29, 221-234. [CrossRef]

30. Ding, J.F.; Kuo, J.F.; Tai, W.H. A fuzzy evaluation model of choosing a middle manager for an international shipping service provider. Brodogradnja 2019, 70, 93-107. [CrossRef]

31. Liao, S.K.; Hsu, H.Y.; Chang, K.L. A novel hybrid MCDM model to select celebrity endorser for airlines. J. Mult.-Valued Log. Soft Comput. 2019, 32, 477-497.

32. Nabeeh, N.A.; Smarandache, F.; Abdel-Basset, M.; El-Ghareeb, H.A.; Aboelfetouh, A. An integrated neutrosophic-TOPSIS approach and its application to personnel selection: A new trend in brain processing and analysis. IEEE Access 2019, 7, 29734-29744. [CrossRef]

33. Pehlivan, N.Y.; Ünal, Y.; Kahraman, C. Player selection for a national football team using fuzzy AHP and fuzzy TOPSIS. J. Mult.-Valued Log. Soft Comput. 2019, 32, 369-405.

34. Yalçın, N.; Pehlivan, N.Y. Application of the fuzzy CODAS method based on fuzzy envelopes for hesitant fuzzy linguistic term sets: A case study on a personnel selection problem. Symmetry 2019, 11, 493. [CrossRef]

35. Carayannis, E.G.; Ferreira, J.J.M.; Jalali, M.S.; Ferreira, F.A.F. MCDA in knowledge-based economies: Methodological developments and real world applications. Technol. Forecast. Soc. Chang. 2018, 131, 1-3. [CrossRef]

36. Ferreira, F.A.F.; Marques, C.S.E.; Reis, M.M.; Ferreira, N.C.M.Q.F.; Çipi, A. Evolutionary patterns and development prospects for e-government: A Delphi-based approach to perceptions of the administrative agent. J. Bus. Econ. Manag. 2015, 16, 18-36. [CrossRef]

37. Dalkey, N.; Helmer, O. An experimental application of the Delphi method to the use of experts. Manag. Sci. 1963, 9, 458-467. [CrossRef]

38. Ferreira, F.A.F.; Santos, S.P. Comparing trade-off adjustments in credit risk analysis of mortgage loans using AHP, Delphi and MACBETH. Int. J. Strateg. Prop. Manag. 2016, 20, 44-63. [CrossRef]

39. Kuo, Y.F.; Chen, P.C. Constructing performance appraisal indicators for mobility of the service industries using fuzzy Delphi method. Expert Syst. Appl. 2008, 35, 1930-1939. [CrossRef] 
40. Hsu, Y.L.; Lee, C.H.; Kreng, V.B. The application of Fuzzy Delphi Method and Fuzzy AHP in lubricant regenerative technology selection. Expert Syst. Appl. 2010, 37, 419-425. [CrossRef]

41. Dong, J.; Huo, H.; Liu, D.; Li, R. Evaluating the comprehensive performance of demand response for commercial customers by applying combination weighting techniques and fuzzy VIKOR approach. Sustainability 2017, 9, 1332. [CrossRef]

42. Murray, T.J.; Pipino, L.L.; van Gigch, J.P. A pilot study of fuzzy set modification of Delphi. Hum. Syst. Manag. 1985, 5, 76-80. [CrossRef]

43. Ishikawa, A.; Amagasa, M.; Shiga, T.; Tomizawa, G.; Tatsuta, R.; Mieno, H. The max-min Delphi method and fuzzy Delphi method via fuzzy integration. Fuzzy Sets Syst. 1993, 55, 241-253. [CrossRef]

44. Hsu, T.H.; Yang, T.H. Application of fuzzy analytic hierarchy process in the selection of advertising media. J. Manag. Syst. 2000, 7, 19-40.

45. Chang, H.Y.; Wu, M.Y.; Sheu, D.F. Perceptions of intellectual capital held by the supervisors of nursing divisions in hospitals in Taiwan. Manag. Decis. 2014, 52, 1101-1115. [CrossRef]

46. Hwang, K.P.; Lin, C.K.; Hsu, C.H. A joint fuzzy AHP approach in prioritizing urban off-street parking sites. J. Chin. Inst. Transp. 2005, 17, 281-304.

47. Wu, H.Y. Constructing a strategy map for banking institutions with key performance indicators of the balanced scorecard. Eval. Program Plan. 2012, 35, 303-320. [CrossRef]

48. Liao, S.K.; Hsu, H.Y.; Chang, K.L. A hybrid multiple criteria decision making model for selecting the location of women's fitness centers. Math. Probl. Eng. 2018, 2018, 9780565. [CrossRef]

49. Liao, S.K.; Hsu, H.Y.; Chang, K.L. OTAs selection for hot spring hotels by a hybrid MCDM model. Math. Probl. Eng. 2019, 2019, 4251362. [CrossRef]

50. Liu, Y.; Yang, Y.; Liu, Y.; Tzeng, G.H. Improving sustainable mobile health care promotion: A novel hybrid MCDM method. Sustainability 2019, 11, 752. [CrossRef]

51. Si, S.L.; You, X.Y.; Liu, H.C.; Zhang, P. DEMATEL technique: A systematic review of the state-of-the-art literature on methodologies and applications. Math. Probl. Eng. 2018, 2018, 3696457. [CrossRef]

52. Saaty, T.L. Decision Making with Dependence and Feedback: The Analytic Network Process; RWS Publication: Pittsburgh, PA, USA, 1996.

53. Sipahi, S.; Timor, M. The analytic hierarchy process and analytic network process: An overview of applications. Manag. Decis. 2010, 48, 775-808. [CrossRef]

54. Hwang, C.L.; Yoon, K. Multiple Attribute Decision Making, Methods and Applications, Lecture Notes in Economics and Mathematical Systems, 186; Springer: New York, NY, USA, 1981.

55. Chen, Y.C.; Yang, C.H.; Chang, K.L. Applying fuzzy multi-criteria decision method to the evaluation of the hosts of Taiwan TV-shopping channels. J. Commun. Manag. 2007, 8, 1-22.

56. Liao, S.K.; Chang, K.L. Select televised sportscasters for Olympic Games by analytic network process. Manag. Decis. 2009, 47, 14-23. [CrossRef]

57. Chang, K.L. Selecting the hosts of Taiwan TV-shopping channels by analytic network process. J. Hum. Resour. Adult Learn. 2007, 3, 103-107.

58. Ziemba, P. Inter-criteria dependencies-based decision support in the sustainable wind energy management. Energies 2019, 12, 749. [CrossRef]

59. Ziemba, P.; Watróbski, J.; Zioło, M.; Karczmarczyk, A. Using the PROSA method in offshore wind farm location problems. Energies 2017, 10, 1755. [CrossRef]

(C) 2020 by the authors. Licensee MDPI, Basel, Switzerland. This article is an open access article distributed under the terms and conditions of the Creative Commons Attribution (CC BY) license (http://creativecommons.org/licenses/by/4.0/). 